\title{
Modification of Cooper's 12-min Run Test to Predict Maximum Oxygen Uptake in Indian Cricketers
}

\section{Amit Bandyopadhyay}

Sports \& Exercise Physiology Laboratory, Department of Physiology, University of Calcutta, University Colleges of Science and Technology, 92 A. P. C. Road, Kolkata: 700009, India.

*Corresponding author Phone: +91 3323508386 (Extension 317) ; Fax: +91 33 23519755; email: bamit74@yahoo.co.in DOI: https://doi.org/10.34256/ijpefs2029

Received: 02-05-2020, Accepted: 17-06-2020

Abstract: Cooper's 12-minute run test (CRT) for prediction of maximum oxygen uptake $\left(\mathrm{VO}_{2 \mathrm{max}}\right)$ has not yet been explored in Indian sportspersons. Present investigation was conducted to evaluate the applicability of CRT in Indian cricketers. 75 male and 45 female cricket players were randomly recruited from reputed cricket academies of Kolkata, India and were randomly assigned into the study group (male $=45$, female $=25$ ) and confirmatory group (male $=30$, female $=20$ ). Incremental cycle ergometer exercise was used for direct estimation of $\mathrm{VO}_{2 \max }$ by expired gas analysis and the indirect prediction of $\mathrm{VO}_{2 \max }\left(\mathrm{PVO}_{2 \max }\right)$ was performed by CRT method. The current protocol of CRT was found to be inapplicable in both the genders of Cricketers due to a significant difference between $\mathrm{PVO}_{2 \max }$ and $\mathrm{VO}_{2 \max }$ and a large limit of agreement between $\mathrm{PVO}_{2 \max }$ and $\mathrm{VO}_{2 \max }$ in the study groups. $\mathrm{A}$ significant correlation ( $r=0.76$ in males and $r=0.79$ in females, $p<0.001$ ) was depicted between $\mathrm{VO}_{2 \max }$ and distance covered in CRT. Regression equations were computed based on the significant correlation. The application of these equations in the confirmatory groups revealed an insignificant difference between $\mathrm{PVO}_{2 \max }$ and $\mathrm{VO}_{2 \max }$ and narrow limits of agreement. Standard errors of the estimate of the regression norms were also minimal. Therefore, modified equations are recommended for CRT application for valid and precise evaluation of cardiorespiratory fitness in terms of $\mathrm{VO}_{2 \max }$ in male and female Indian cricketers.

Keywords: Cooper test, Cricket, $\mathrm{VO}_{2 \max }$, Oxygen uptake, Cricketers

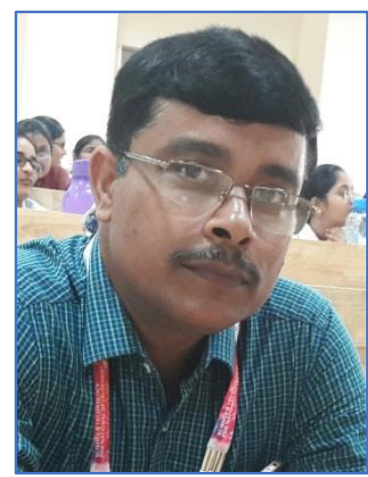

Amit BANDYOPADHYAY Ph.D, Assistant Professor, Department of Physiology and Guest Faculty of Sports Science Department, University of Calcutta, has been actively involved in teaching Physiology and research in the fields of Sports and Exercise Physiology, Sports Nutrition, and Work Physiology since last 20 years. Besides his long association as Guest Faculty of Physiology in Post-Graduate Departments of different Universities and Colleges of West Bengal, India, he also served as a Senior Lecturer, School of Health Sciences, Universiti Sains Malaysia for three years. Dr. Bandyopadhyay is a Fellow of the International College of Nutrition, Honorary Treasurer of The Physiological Society of India and life member of Indian Science Congress Association, Federation of Indian Physiological Societies, South Asian Association of Physiologists, Federation of the Asian and Oceanian
Physiological Society. Also, he serves as an Editorial Board Member and Reviewer in peer-reviewed Journals of international repute. He is a recipient of many prestigious awards, including the National Scholarship Scheme and Prof. B.B. Sarkar Memorial Research Prize (PSI). In 2014, he was honored as an "International Invitee" by the Physiological Society of the UK to present his most valued research paper.

\section{Introduction}

There is the immense importance of maximum oxygen uptake $\left(\mathrm{VO}_{2 \max }\right)$ in sports and exercise science. It is globally considered as the best parameter to judge an individual's cardiorespiratory fitness. Direct estimation of $\mathrm{VO}_{2 \max }$ is confined within the laboratory due to its difficult, expensive and complicated experimental protocol [1]. Therefore, it is required to explore the indirect procedure for the evaluation of $\mathrm{VO}_{2 \max }$. This will help to evaluate the cardiorespiratory 
fitness in the field and in the absence of well-equipped laboratory [2].

Non-exercise based norms in the form of the regression equation for the indirect evaluation of $\mathrm{VO}_{2 m a x}$ from body fat percentage is available in Indian college students $[3,4]$. 3 min walking distance concerning gender, age and body composition has been proposed in Japanese adults [5]. At the same time Huntsman et al., [6] developed a field test for the indirect prediction of $\mathrm{VO}_{2 m a x}$ in rowers by restricting the use of equipment and laboratory infrastructure. American College of Sports Medicine (ACSM) proposed a submaximal treadmill running test for prediction of $\mathrm{VO}_{2 \max }$ and it was validated by Marsh [7] in 18-34 years of moderately trained men [7]. Literature about the indirect prediction of $\mathrm{VO}_{2 \max }$, suggest that all the protocols should use inexpensive instrument and minimum infrastructure to predict the cardiorespiratory fitness and the tests need to be validated in a particular population before its execution.

One of the popular indirect methods of $\mathrm{VO}_{2 \max }$ prediction is Cooper's 12-minute run test (CRT) that only needs a measuring tape to measure the distance covered in $12 \mathrm{~min}$. Like, other methods, this test was also invented and standardized in the Western population. Therefore, applying this test in any other community requires appropriate enumeration of the test's validity.

The validity of some of the commonly used indirect protocols for prediction of $\mathrm{VO}_{2 \max }$ has been explored in sedentary Indian populations. But similar studies are unavailable in Indian sportspersons. The present investigation was therefore aimed to evaluate the applicability of CRT to predict $\mathrm{VO}_{2 \max }$ in male and female Indian cricket players of Kolkata, West Bengal, India.

\section{Materials and Methods}

\subsection{Study Population}

Male $(n=75)$ and female $(n=45)$ cricket players (age range 20 to 25 years) were selected for the study from reputed cricket academies of Kolkata, India, by simple random sampling. They had at least 5 years of regular participation in the training programme. PSPower and Sample Size Calculation version 3.0.43 was used to calculate the sample size [8]. Recruited subjects were randomly separated into study group ( male $=45$, female $=25$ ) and confirmatory group (male $=30$, female $=20$ ). Available experimental protocol of CRT was tested on the study group and a modified norm in the form of a regression equation was computed. This modified equation was applied in the confirmatory group to judge the suitability of this newly computed equation in the studied population.

To allay apprehension, all the subjects were elaborated about the experimental protocol. They were asked not to take part in any exercise or heavy work on the evaluation days. The participants were free from any medication during the study period and they did not report any history of suffering from any major diseases.

The study period was August 2018 to December 2019. The entire work was conducted at a varying temperature of $27-35^{\circ} \mathrm{C}$ and at a relative humidity ranging between 52 to $70 \%$. Human ethical clearance for the study was obtained from the Institutional Human Ethical Committee. Written informed consent was obtained from all the subjects.

\subsection{Experimental design}

Cross-over design was adopted to estimate the maximum oxygen consumption by direct and indirect (CRT) methods with a minimum interval of 4 days in between the tests. Heart rates were recorded by using a Polar heart rate monitor. Before to advocating the exercise tests, subjects took rest for 30 min to enable the cardiorespiratory parameters to reach a steady state $[1,2]$.

\subsection{Prediction of maximum oxygen uptake capacity (PVO 2 max) by CRT (Cooper, 1968):}

Subjects were asked to run for a total duration of 12 min with maximum possible pace on a 400 meter round track. They were motivated with verbal encouragement to ensure maximum performance. The total distance covered was measured by counting the number of laps they completed and by marking the finishing point. The total distance covered during this 12 min run was measured in $\mathrm{km}$ and the value was put in the following equation to predict the $\mathrm{VO}_{2 \max }$ [9]:

$\mathrm{VO}_{2 \max }\left(\mathrm{ml} \cdot \mathrm{kg}^{-1} \cdot \mathrm{min}^{-1}\right)=(22.351 \times$ Distance covered in kilometers) - 11.288

\subsection{Direct measurement of maximum oxygen uptake capacity ( $\left.\mathrm{VO}_{2 \max }\right)$}

The direct estimation of $\mathrm{VO}_{2 \max }$ was performed by following the protocol of Chatterjee et al., [1] and Chatterjee et al., [2] for male and female cricketers, 
respectively, by exercising on Muller's magnetic brake bicycle ergometer (Model of Max Plank Institute of Ergology, Germany). Criteria for the attainment of maximum oxygen consumption were set according to earlier studies [1, 2].

Expired gas was collected in a Douglas bag $(150 \mathrm{~L})$ by open circuit method at the last minute of the final intensity of an exercise by using a high velocity Collin's Triple "J Type" plastic valve [1, 2]. A wet gasometer (Toshniwal, Germany, CAT. No. CG05.10) was used to measure the expired air and an aliquot of the expired gas sample was analyzed in Scholander micro-gas analyzer [10].

\subsection{Statistical analysis}

A significant difference between means of $\mathrm{VO}_{2 \max }$ and $\mathrm{PVO}_{2 \max }$ was tested by the Paired t-test. Pearson's product moment correlation test was applied to evaluate the relationship between $\mathrm{VO}_{2 \max }$ and distance covered in CRT. Computation of regression equation between maximum oxygen uptake (dependant variable) and distance covered in CRT (independent variable) was performed by linear regression statistic. Applicability of the existing protocol and the newly derived equation in the studied population was tested by Bland and Altman approach for the limit of agreement analysis [11].

\section{Results and Discussion}

The physical and physiological characteristics as was well as the distance covered in CRT by male and female cricketers have been presented in table 1 . A significant difference in body weight, body height and distance covered in CRT was found between male and female groups (Table 1).
Bland and Altman approach for limit of agreement analysis in case of the cricketers of both the genders has been plotted in Fig 1 and 2 .

A significant correlation was observed between $\mathrm{VO}_{2 \max }$ and distance covered in CRT in male $(r=0.76$, $p<0.001)$ and female $(r=0.79, p<0.001)$ cricketers. Regression norms have been computed in both the gender groups of cricket players for the prediction of $\mathrm{VO}_{2 \max }$ from a distance covered in CRT (Fig 3 and Fig 4).

A noteworthy difference was found between $\mathrm{PVO}_{2 \max }\left(60.25 \pm 3.95 \mathrm{ml} . \mathrm{kg}^{-1} \cdot \mathrm{min}^{-1}\right.$ in males and $51.78 \pm 3.81 \mathrm{ml} \cdot \mathrm{kg}^{-1} \cdot \mathrm{min}^{-1}$ in females) and $\mathrm{VO}_{2 \max }$ $\left(51.57 \pm 4.11 \mathrm{ml} \cdot \mathrm{kg}^{-1} \cdot \mathrm{min}^{-1}\right.$ in males and $47.15 \pm 4.26$ $\mathrm{ml} . \mathrm{kg}^{-1} \cdot \mathrm{min}^{-1}$ in females) in the study groups of male and female cricketers. Large limits of agreement were noted between $\mathrm{PVO}_{2 \max }$ and $\mathrm{VO}_{2 \max }$ (2.83 to 14.63 $\mathrm{ml} \cdot \mathrm{kg}^{-1} \cdot \mathrm{min}^{-1}$ in males and 4.18 to $14.54 \mathrm{ml} \cdot \mathrm{kg}^{-1} \cdot \mathrm{min}^{-1}$ in females) with poor confidence intervals when the data were analyzed by Bland and Altman method [11] (Fig 1 and Fig 2). These findings indicated that the existing protocol of CRT, as proposed by Cooper [9], is not applicable in this particular population.

Significant positive correlation was observed between distance covered in CRT and directly measured values of $\mathrm{VO}_{2 \max }$ in male and female cricketers ( $r=0.76$ in males and $r=0.79$ in females, $\mathrm{p}<0.001$ ) belonging to the study groups. Prediction equations for $\mathrm{VO}_{2 \max }$ from distance covered in CRT were computed in male $[\mathrm{Y}=8.75 \mathrm{X}+21.85$ (SEE $=$ $\left.\left.2.69 \mathrm{ml} \cdot \mathrm{kg}^{-1} \cdot \mathrm{min}^{-1}\right)\right]$ and female $[Y=19.99 \mathrm{X}-13.74$ $\left.\left(\mathrm{SEE}=2.62 \mathrm{ml} \cdot \mathrm{kg}^{-1} \cdot \mathrm{min}^{-1}\right)\right]$ cricketers for more accurate and reliable assessment of $\mathrm{VO}_{2 \max }$ in the studied population (Fig 3 and Fig 4).

Table 1 Physical and physiological parameters of the male and female cricketers.

\begin{tabular}{|c|c|c|c|c|c|c|c|c|}
\hline \multirow[t]{2}{*}{ Group } & \multirow[t]{2}{*}{$\begin{array}{l}\text { Gender } \\
\text { Group }\end{array}$} & \multirow[t]{2}{*}{$\begin{array}{l}\text { Age } \\
\text { (Yrs) }\end{array}$} & \multirow{2}{*}{$\begin{array}{c}\text { Body } \\
\text { weight } \\
(\mathbf{k g})\end{array}$} & \multirow{2}{*}{$\begin{array}{c}\text { Body } \\
\text { height } \\
(\mathrm{cm})\end{array}$} & \multirow{2}{*}{$\begin{array}{c}\text { Pre-Exercise } \\
\text { Heart rate } \\
\left(\text { beats. } \mathrm{min}^{-1}\right)\end{array}$} & \multicolumn{2}{|c|}{$\begin{array}{l}\text { Blood Pressure } \\
\text { ( } \mathrm{mm} \text { of } \mathrm{Hg} \text { ) }\end{array}$} & \multirow{2}{*}{$\begin{array}{c}\text { Distance } \\
\text { covered in } \\
\text { CRT }(\mathbf{k m})\end{array}$} \\
\hline & & & & & & Systolic & Diastolic & \\
\hline \multirow{3}{*}{ Cricketer } & Male & 22.82 & 68.62 & $175.04 \pm$ & 66.81 & 103.24 & 67.41 & 3.395 \\
\hline & $(n=75)$ & \pm 1.76 & \pm 4.23 & 4.31 & \pm 4.63 & \pm 5.42 & \pm 4.27 & \pm 0.36 \\
\hline & $\begin{array}{l}\text { Female } \\
(n=45)\end{array}$ & $\begin{array}{l}22.88 \\
\pm 2.81\end{array}$ & $\begin{array}{c}57.58 \\
\pm 4.29 *\end{array}$ & $\begin{array}{c}168.62 \pm \\
4.56 *\end{array}$ & $\begin{array}{l}65.74 \\
\pm 5.84\end{array}$ & $\begin{array}{c}101.73 \\
\pm 6.71\end{array}$ & $\begin{array}{l}64.65 \\
\pm 3.95\end{array}$ & $\begin{array}{c}3.045 \\
\pm 0.17^{*}\end{array}$ \\
\hline
\end{tabular}

Values are mean $\pm S D, * p<0.001$ 


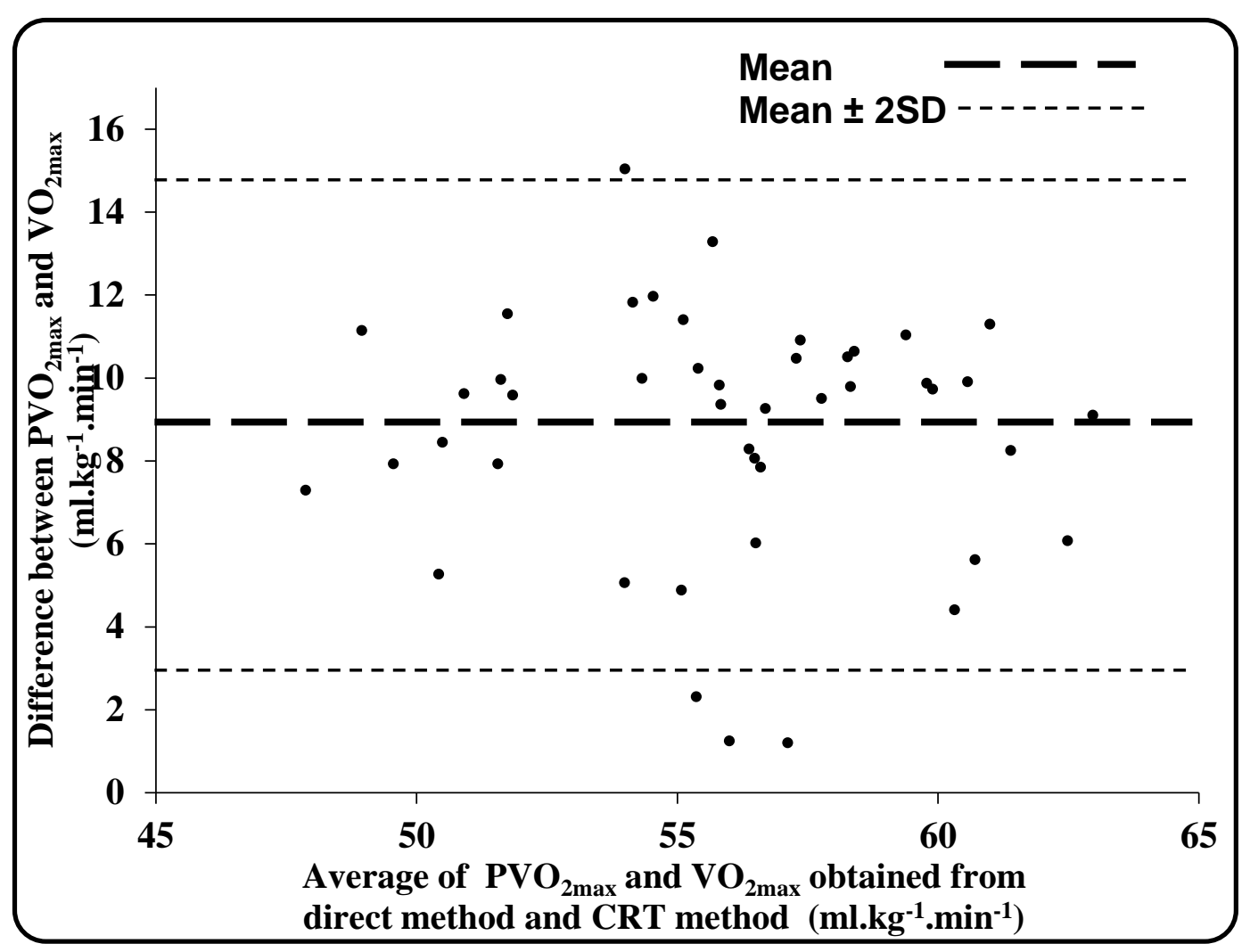

Figure 1 Representation of difference between $\mathrm{PVO}_{2 \max }$ and $\mathrm{VO}_{2 \max }$ in the study group of male cricketers by plotting the data against their mean values.

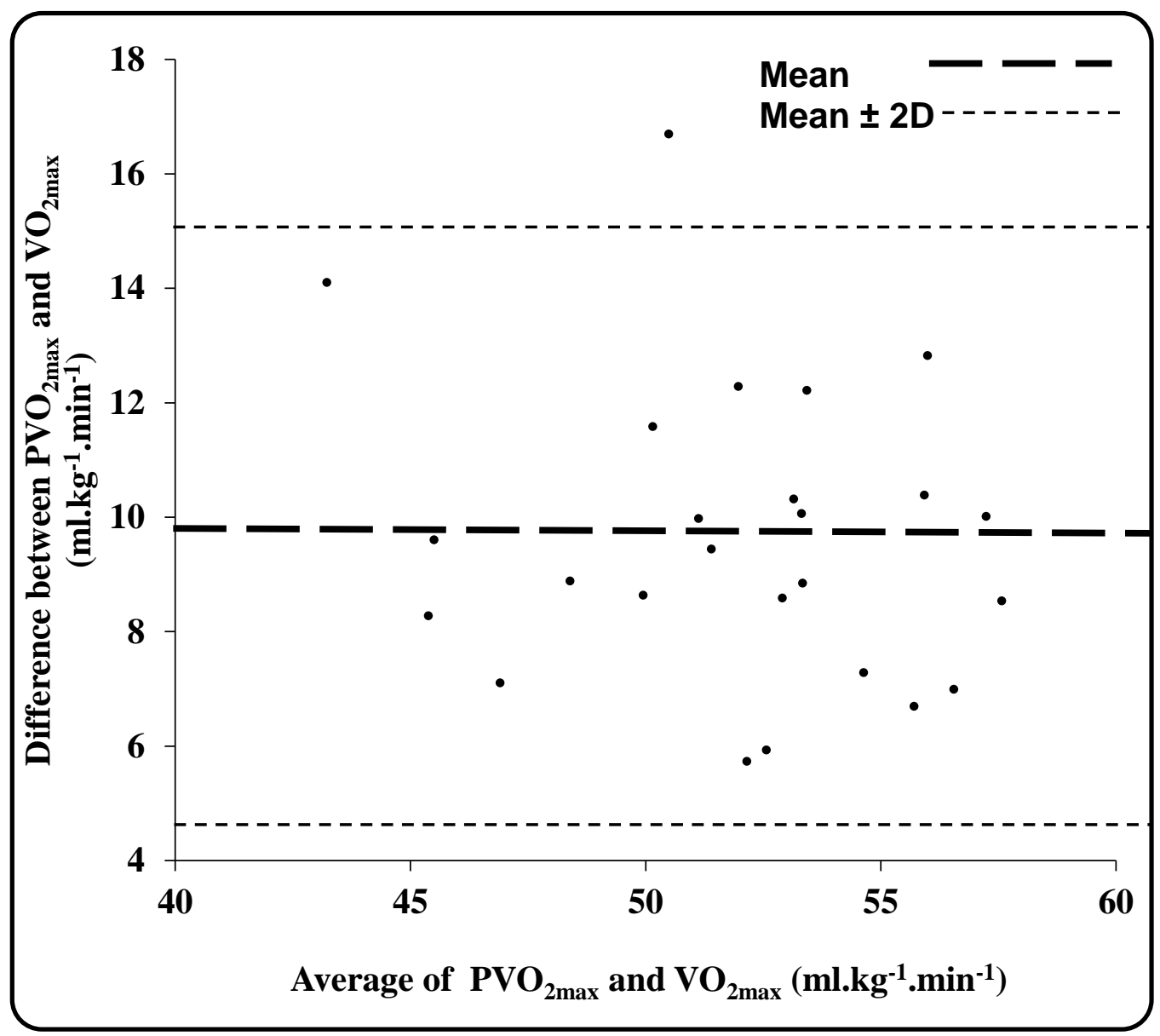

Figure 2 Representation of difference between $\mathrm{PVO}_{2 \max }$ and $\mathrm{VO}_{2 \max }$ in the study group of female cricketers by plotting the data against their mean values. 


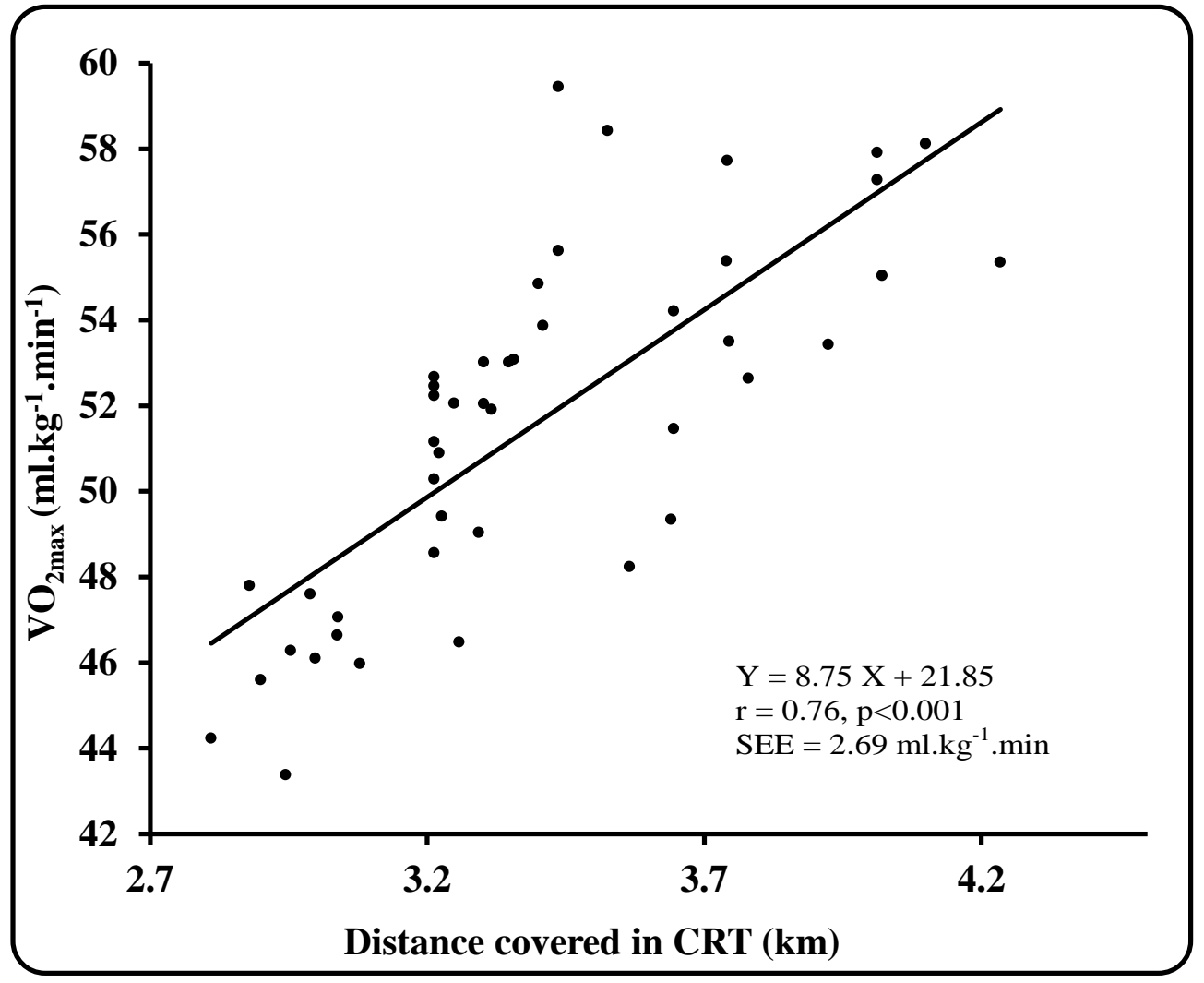

Figure 3 Results of correlation and regression analysis in the study group of male cricketers.

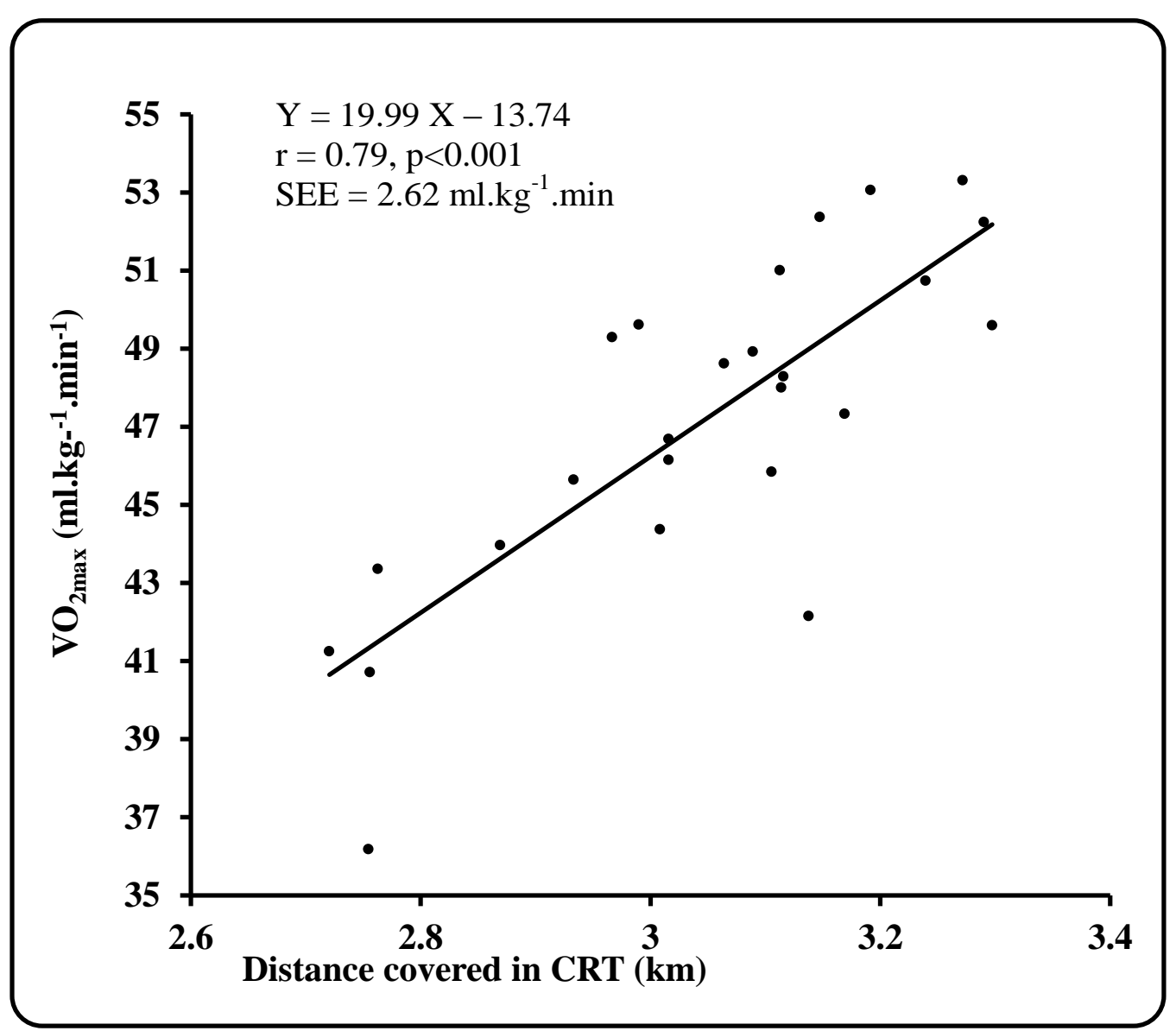

Figure 4 Results of correlation and regression analysis in the study group of female cricketers. 
Insignificant difference between $\mathrm{PVO}_{2 \max }$ (53.34 $\pm 3.94 \mathrm{ml} \cdot \mathrm{kg}^{-1} \cdot \mathrm{min}^{-1}$ in males and $47.81 \pm 3.65$ $\mathrm{ml} \cdot \mathrm{kg}^{-1} \cdot \mathrm{min}^{-1}$ in females) and $\mathrm{VO}_{2 \max }(52.59 \pm 4.24$ $\mathrm{ml} \cdot \mathrm{kg}^{-1} \cdot \mathrm{min}^{-1}$ in males and $48.27 \pm 3.50 \mathrm{ml} \cdot \mathrm{kg}^{-1} \cdot \mathrm{min}^{-1}$ in females) was found when these modified equations were applied in the respective confirmatory group of male and female cricketers. Further analysis of $\mathrm{VO}_{2 \max }$ and $\mathrm{PVO}_{2 \max }$ data to test the reliability of these modified equations in the confirmatory group by using Bland and Altman's limit of agreement approach revealed substantially small limits of agreement in male ( -0.92 to $\left.2.08 \mathrm{ml} \cdot \mathrm{kg}^{-1} \cdot \mathrm{min}^{-1}\right)$ and female ( -0.4 to 1.64 $\left.\mathrm{ml} \cdot \mathrm{kg}^{-1} \cdot \mathrm{min}^{-1}\right)$ groups. The percentage of variation between $\mathrm{VO}_{2 \max }$ and $\mathrm{PVO}_{2 \max }$ reduced from $16.83 \%$ to $1.42 \%$ in male cricketers and from $9.826 \%$ to $2.26 \%$ in female cricketers following application of the revised population specific equations.

Testing of repeatability of the modified equations as per the guideline of Bland and Altman [11] observed that the mean difference between repeated measures of directly measured and indirectly predicted $\mathrm{VO}_{2 \max }$ was insignificantly different from zero in both the genders. This observation met the criterion of "Repeatability Coefficient" by representing $95 \%$ or, more of the differences were less than two standard deviations ( $\pm 2 \mathrm{SDs})[12]$. The mean differences of repeated measures for modified equations in males and females were $0.0051 \mathrm{ml} \cdot \mathrm{kg}^{-1} \cdot \mathrm{min}^{-1}$ and 0.0049 $\mathrm{ml} . \mathrm{kg}^{-1} \cdot \mathrm{min}^{-1}$ respectively, whereas the differences of repeated measures for the direct method were 0.0042 $\mathrm{ml} \cdot \mathrm{kg}^{-1} \cdot \mathrm{min}^{-1}$ and $0.0038 \mathrm{ml} \cdot \mathrm{kg}^{-1} \cdot \mathrm{min}^{-1}$ in male and female groups, respectively. Subsequent values of Repeatability Coefficients were $\pm 0.34 \mathrm{ml} \cdot \mathrm{kg}^{-1} \cdot \mathrm{min}^{-1}$, $\pm 0.30 \mathrm{ml} \cdot \mathrm{kg}^{-1} \cdot \mathrm{min}^{-1}, \pm 0.31 \mathrm{ml} \cdot \mathrm{kg}^{-1} \cdot \mathrm{min}^{-1}$ and \pm 0.28 $\mathrm{ml} . \mathrm{kg}^{-1} \cdot \mathrm{min}^{-1}$, respectively.

\section{Conclusion}

The present investigation revealed that the original equation of Cooper's 12 min run test is not applicable for the prediction of $\mathrm{VO}_{2 \max }$ in male and female Indian cricketers. However, the modified equations have predicted the $\mathrm{VO}_{2 \max }$ quite precisely in the studied population. The standard errors of estimate (SEE) of these norms are also substantially small. The equations derived in the present study are recommended for evaluation of $\mathrm{VO}_{2 \max }$ by using Cooper's 12 min run test in male and female cricketer players of Kolkata, West Bengal, India.

\section{References}

[1] S. Chatterjee, P. Chatterjee, P.S. Mukherjee, A. Bandyopadhyay, Validity of Queen's College step test for use with young Indian men, British Journal of Sports Medicine, 38 (2004) 289-291. http://dx.doi.org/10.1136/bjsm.2002.002212

[2] S. Chatterjee, P. Chatterjee, A. Bandyopadhyay, Validity of Queen's College Step Test for estimation of maximum oxygen uptake in female students, Indian Journal of Medical Research, 121 (2005) 32-5.

[3] S. Shenoy, B.S. Tyagi, J.S. Sandhu, Concurrent validity of the non-exercise based $\mathrm{VO}_{2 \max }$ prediction equation using percentage body fat as a variable in asian Indian adults, Sports Medicine, Arthroscopy, Rehabilitation, Therapy \& Technology, 4 (2012) 34.

https://doi.org/10.1186/1758-2555-4-34

[4] S. Shenoy, B. Tyagi, J. Sandhu, D. Sengupta, Development of non-exercise based $\mathrm{VO}_{2 \max }$ prediction equation in college-aged participants in India, The Journal of sports medicine and physical fitness, 52 (2012) 465-473.

[5] Z.B. Cao, N. Miyatake, T. Aoyama, M. Higuchi, I. Tabata, Prediction of maximal oxygen uptake from a 3-minute walk based on gender, age, and body composition, Journal of Physical Activity and Health, 10(2) (2013) 280-287.

https://doi.org/10.1123/jpah.10.2.280

[6] H.D. Huntsman, L. DiPietro, D.G. Drury, T.A. Miller, Development of a Rowing-Specific O2max Field Test, The Journal of Strength \& Conditioning Research, 25 (2011) 1774-1779. https://doi.org/10.1519/JSC.0b013e3181e4f7a9

[7] C.E. Marsh, Evaluation of the American College of Sports Medicine submaximal treadmill running test for predicting $\mathrm{VO}_{2 \max }$, The Journal of Strength \& Conditioning Research, 26 (2012) 548-554.

https://doi.org/10.1519/JSC.0b013e318220d9a8

[8] W.D. Dupont, W.D. Jr Plummer, Power and sample size calculations for studies involving linear regression, Controlled clinical trials, 19 (1998) 589-601.

https://doi.org/10.1016/S0197-2456(98)00037-3

[9] K.H. Cooper, A means of assessing maximal oxygen intake: correlation between field and treadmill testing, Journal of the American Medical Association, 203 (1968) 201-204.

https://doi.org/10.1001/jama.1968.03140030033008 
[10] C.F. Consolazio, L.J. Pecora, Physiological measurements of metabolic functions in man, (1963) McGrawHill Publishing Co. Ltd, London.

[11] J. Martin Bland, Douglas G Altman. Statistical methods for assessing agreement between two methods of clinical measurement. The lancet, 327 (1986) 307-310.

https://doi.org/10.1016/S0140-6736(86)90837-8

[12] British Standards Institution. Precision of test methods 1: Guide for the determination and reproducibility for a standard test method (BS 597, Part 1). London: BSI 1975.

\section{Acknowledgement}

Author is indebted to the players who had participated in the study.

\section{Informed consent}

All participants gave written informed consents to participate in this study.

\section{Funding}

Departmental contingency grant of Budget Head BI92(7) of University of Calcutta was used for the study

\section{Conflict of interest}

None of the authors have any conflicts of interest to declare.

\section{About The License \\ (C) The author(s) 2020. The text of this article is open access and licensed under a Creative Commons Attribution 4.0 International License}

